\title{
AS RELAÇÕES ENTRE OS PODERES ESPIRITUAL E TEMPORAL NA TEORIA POLÍTICA DE ÁLVARO PELAYO ATRAVÉS DE SEU SPECULUM REGUM
} (1341-1344)

Leonardo Girardi ${ }^{1}$

Resumo: Intentamos por meio deste artigo explorar a forma como o Poder Espiritual se articulou diante da nova realidade que começa a se esboçar por entre os séculos XIV e XV. Por ser o meio clerical nosso objeto central, é através de seu prisma que iremos analisar o contexto da Baixa Idade Média, elegendo para tal os trabalhos de Frei Álvaro Pelayo (c. 1270-1352), os quais bem explícita sua teoria política. Através das prerrogativas contidas em sua obra Speculum Regum (redigida entre 13411344), analisaremos alguns dos argumentos de ordem espiritual na tentativa de defesa da já combalida soberania eclesiástica sobre o Poder Temporal, observando também de que modo estes se articulam com o contexto da centralização do poder em torno da figura régia em Portugal.

Palavras-chave: Baixa Idade Média, Portugal, Teoria Política, Álvaro Pelayo, Speculum Regum, Poder Espiritual e Poder Temporal.

\section{Introdução}

Álvaro Pelayo esteve profundamente ligado às questões de seu tempo. Tal colocação consta como uma máxima bastante recorrente em boa parte da historiografia dedicada especificamente ao frei galego ${ }^{2}$. Entretanto, podemos dizer que a mesma tem o seu fundo de embasamento,

\footnotetext{
${ }^{1}$ Aluno do $6^{\circ}$ período de graduação do curso de História - Licenciatura e Bacharelado, da Universidade Federal do Paraná. Esta pesquisa é orientada pela Prof. ${ }^{a}$ Dr. ${ }^{a}$ Fátima Regina Fernandes. Link do Lattes: http://buscatextual.cnpq.br/ buscatextual/visualizacv.do?id=H8069553

${ }^{2} \mathrm{E}$ aqui destacamos especialmente os trabalhos desenvolvidos por José Antônio de C. R. de Souza, Armênia Maria de Souza e Morais Barbosa.
} 
principalmente se nos pautarmos no fato de Álvaro Pelayo haver se detido longamente nos grandes debates que moveram a primeira metade do século XIV - a saber, dentre outros mais, a centralização do poder real e a disputa Sacerdócio/Império, temas estes que nos debruçaremos ao longo deste trabalho - e formulado sua teoria política como reflexo, ou, em resposta a eles.

Em trabalho anterior, tivemos a oportunidade de analisar o Cisma do Ocidente (1378-1417) sob o foco da política pendular do soberano D. Fernando I de Portugal (1367-1383) tendo em vista assim, as relações políticas que envolvem as esferas espiritual e temporal do poder (GIRARDI, 2012). Agora, recuamos nosso foco analítico para aproximadamente quarenta anos antes dos eventos tratados anteriormente, a fim de explorarmos melhor as causas que desencadearam a série de querelas e comoções que movimentaram o final do século XIV e início do XV, bem como melhor explorar este período transitório do Medievo para a Modernidade. Sendo assim, temos como evento principal a se desenrolar dentro da Cristandade latina o chamado Exílio de Avignon (1309-1377), compreendido pela ausência da Cúria Pontifícia da cidade de Roma e sua consequente instalação em Avignon, França, culminando na sujeição da Cúria à coroa dos francos ${ }^{3}$.

${ }^{3}$ O Exílio de Avignon compreende o período de cerca de setenta anos (13091378) em que a Cúria Pontifícia esteve ausente da Cidade Eterna, causada por sua transferência à cidade francesa de Avignon, de forma que o Papado mantivesse-se sob a tutela dos soberanos franceses, além de dar fim às suas pretensões de concretizar a chamada Teocracia Pontifícia. Embora o acontecimento possa ser encarado como um período de completo desastre para a Igreja, Avignon se tornou um importante centro cultural, ponto de parada nas rotas que perpassavam a Cristan- 
Tal acontecimento é importante por marcar a ascensão dos poderes régios em paralelo aos últimos suspiros dos sonhos pontifícios de um primado de caráter político sobre os reinos do Ocidente, o qual encontrou durante muito tempo seu sustento em teorias elaboradas por grandes doutos da Igreja. Neste sentido, podemos mencionar o duelo que se desenvolveu no próprio interior da Instituição, evocando nomes como o de Marsílio de Pádua, Guilherme de Ockham - de tantos outros -, que atuaram como vorazes críticos das ideias contidas na teocracia pontifícia; e em contrapartida, evocam-se aqueles que se empenharam na construção de defesas e ofensivas a esses críticos, observando-se aqui Egídio Romano, Tiago de Viterbo e, Álvaro Pelayo. Centramos assim nossos esforços neste último, eminente frei galego e bispo de Silves (Portugal), que veio a ter importante destaque no cenário ibérico - sobretudo português - por meio de seus posicionamentos políticos veiculados através de seus escritos, os quais tomaremos como fonte primária o Espelho dos Reis (Speculum Regum - 1341-1344), obra esta em que o frei deixa muito bem clara a sua concepção de supremacia do Sacerdotium sobre o Imperium ou, de maneira mais sintética, do poder espiritual sobre o temporal. Desta forma, rapidamente introduziremos o contexto em que autor e obra estão inseridos, para no momento seguinte, analisarmos detidamente as premissas contidas na fonte, dedicada a Afonso XI, o Justiceiro, rei de Castela, mas que pode responder à situação de indisposição do bispo para com o soberano português D. Afonso IV, o Bravo.

dade latina; por consequência, desenvolveu-se ali uma grande e opulenta corte, com um aparato administrativo/burocrático tão desenvolvido quanto aquele outrora encontrado em Roma (KNOWLES \& OBOLENSKI, 1976). 
Cadernos de Clio, Curitiba, n. ${ }^{\circ}$ 4, 2013

\section{Álvaro Pelayo em seu tempo}

Nascido por volta do ano de 1270, sendo quase impossível precisar a data por escassez de dados, sabe-se com certeza da procedência galega de frei Álvaro - mais especificamente de San Juan Del Salnés, Cambados, Província de Pontevedra, pertencente à arquidiocese de Santiago de Compostela. Outro dado de valor é que fora filho bastardo do nobre D. Payo Gómez Chariño, importante almirante da corte castelhana, além de ser considerado como um dos maiores trovadores galegos do século XIII. Por tal posição prestigiosa de seu pai, Álvaro conseguiu ter sua educação garantida em meio à corte de D. Sancho IV, rei de Castela (1284-1295) a quem muito dedicou seu afeto e sempre deveu suas gratidões e elogios estendidos por conseguinte a Alfonso XI, futuro rei (1325-1350) (SOUZA, A. M., 2011; SOUZA, J. A., 2010, 2011).

Para além de sua educação em tal corte,

“[...] em virtude de sua origem bastarda, Álvaro deve ter sido destinado à carreira sacerdotal e, com grande probabilidade de certeza, podemos supor que terá frequentado a renomada escola catedralícia de Compostela, tendo aí recebido uma formação cultural básica e filosófico-teológica bem sólidas a fim de poder exercer a contento seu ministério. [...]” (SOUZA, A. M, 2011: 190).

Fora um “cosmopolita”, nas palavras de Armênia Maria de Souza (SOUZA, A. M, 2011: 190) e podemos atestar tal colocação pela caminhada descrita tanto por esta autora, como por José Antônio de Souza 
(SOUZA, J. A., 2004). Álvaro viveu na Itália, onde cursou Direito na Universidade de Bolonha, possivelmente persuadido por parentes próximos que almejavam sua ascensão na hierarquia eclesiástica - tendo em vista que a Igreja do século XIII estava sendo governada em grande parte por Papas cuja formação era intelectual, destacando-se pela série de juristas: o que atrelava a Igreja mais às ações políticas do que pastorais; esteve em Assis como frade da Ordem Menor de São Francisco, e em seguida na corte papal de Avignon, atuando como penitenciário do Papa João XXII e finalmente, ocupou o bispado da diocese de Silves, em Portugal (atualmente diocese de Faro, no Algarve, sul do país), também eleito para esta função pelo Papa João XXII. Por meio destas informações, podemos perceber o arcabouço intelectual adquirido por Álvaro Pelayo, elemento este que dará forma e sustento ao seu trabalho, reforçando assim a primeira frase que citamos ao inicio de nosso texto: “esteve profundamente ligado às questões de seu tempo”.

Desta ligação com o seu tempo surgiu o conjunto maior de sua obra, composto por três grandes títulos, a saber: De Statu et Planctu Ecclesiae (1330-1332); Speculum Regum (1341-1344); Collyrium Fidei Aduersus Haereses (não há uma data precisa para sua redação, mas sabe-se que é posterior ao ano de 1344). Somando-se a estas, Pelayo redigiu outros três escritos menores: Comentário ao Evangelho de São Mateus, Comentário sobre os Quatro Livros de Sentenças e Sermão sobre a Visão Beatífica (BARBOSA, 1972: 15-19). Na trilogia principal, fica-se clara a atenção do autor para com a Cristandade, sobretudo a Igreja, salientando seus problemas (que foram representados principalmente pelas heresias, por conseguinte, elencadas no Collyrium Fidei...) e dando-lhes soluções, estas 
que perpassam além do mais, pelo conjunto de sua obra. Em seu Speculum Regum $^{4}$ encontramos uma boa lapidação de sua teoria política, vista primeiramente no Statu et Planctu Ecclesiae, dadas às revisões e acréscimos feitos pelo autor. No que tange a atribuições, é interessante mencionar o fato de que esta obra recebe a marca de "primeira obra de filosofia política redigida em Portugal”, o que por si só, atraí nossos interesses e foco de atenção.

Muito embora à época da redação do Speculum Regum as lutas entre o poder espiritual e temporal já estivessem frias e relegadas às brumas do tempo (BARBOSA, 1972), a composição de sua obra denota a força que tais teorias apresentam, sobretudo quando os motivos que impulsionam a sua criação já foram superados - ou seja, o embate entre Papado e Sacro-Império Romano Germânico que por séculos se arrastou até a vitória da Instituição religiosa no século XII. Porém, estas discussões ainda encontram importância por estarem situadas num momento crucial para a forja das bases do Estado moderno, bem como de sua subsequente consolidação, sobretudo se levarmos em conta a expansão da figura régia que mais tarde, culminaria o absolutismo. As relações de poder no reino de Portugal testemunham muito bem a favor de tal prerrogativa afinal, assis-

${ }^{4} \mathrm{O}$ gênero dos Espelhos de Reis, ao qual se insere nossa fonte, corresponde aos tratados doutrinais que objetivavam a instrução de príncipes ao exercício do bom governo através de modelos teóricos de conduta pautados em exemplos cristãos de virtude e ética. Tais tratados baseavam-se na autoridade dos grandes autores pagãos da Antiguidade e nos textos bíblicos, assim bem como nos grandes pensadores medievais. Características como "bom legislador”, “justo” e "protetor da Cristandade” eram bastante evocadas, apontando e em alguns momentos para a contenção da figura régia, objetivo de alguns membros do clero ao redigirem suas obras (DIEHL \& VERÍSSIMO, 2011). 
timos à elevação cada vez maior da figura do rei dentro do cenário político, centralizando em torno de si e de sua autoridade todas as funções administrativas, burocráticas, legislativas, dentre outras do reino - ou seja, um momento impar na História da Idade Média ${ }^{5}$.

Assim sendo, dois fenômenos poderão ser registrados aqui, dentre inúmeros presentes e de destaque no panorama recortado, e que terão relações entre si no que tange à nossa pesquisa: a já mencionada centralização do poder nas mãos do rei (projeto que em Portugal fora iniciado basicamente com Afonso III, levado a cabo com D. Dinis e aprimorado com Afonso IV), e o fim da premissa de Teocracia Pontifícia, frente à sujeição da Cúria de Roma ao reino francês, liderado no período por Filipe, o Belo (1268-1314), e a posterior transferência desta para a cidade francesa de Avignon.

Neste sentido, Oliveira Marques em Portugal na Crise dos Séculos $X I V$ e $X V$ oferece justamente um panorama demasiado detalhado do reino de Portugal em seus vários aspectos (econômico, político, social, religioso...), dentro do marco cronológico de 1320 a 1470. A escolha deste período por sua parte faz jus à crise que acometeu toda a Cristandade latina, caracterizada pela trindade fome, guerra e peste - o reino penínsular não escapou. Muitas mudanças o afetaram, projetando-o de maneira mais incisiva no palco europeu, impulsionando-o à expansão comercial, ou transformando a própria sociedade trinitária, transformação esta onde destacamos principalmente a Nobreza e o Clero por pertencerem ao meio que tratamos: a centralização do poder levou à uma renovação da Nobreza (a

\footnotetext{
${ }^{5}$ Tal fenômeno da centralização do poder ocorre em vários outros reinos da Cristandade latina, senão ao mesmo tempo, de forma semelhante.
} 
Cadernos de Clio, Curitiba, n. ${ }^{\circ}$ 4, 2013

exceção de alguns pequenos fidalgos), e o Clero encontrou dificuldades para se adaptar às novas transformações, burocratizando-se, e secularizando-se, fazendo cada vez mais parte da vida profana (MARQUES, 1986: 279-280).

Mesmo que tenha havido focos de resistência por parte de estruturas medievais mais obsoletas, o predomínio das novas, destacando-se a de governo, centralizado e sob as rédeas do rei, sobressaiu-se como denota o surgimento de uma legislação geral, da instituição do beneplácito régio, da nacionalização de dioceses e ordens militares e, também muito importante, a nova tributação estipulada pela Coroa, que não respeitava privilégio algum, caindo sobre nobres e clérigos, no que fica muito bem exposto pelo trecho a seguir:

“[...] o Rei e a burocracia da Coroa invadiam as prerrogativas dos senhores, interferiam nas suas terras, sobrepunham-lhes uma doutrina, uma autoridade e um centralismo que violavam todos os seus direitos e tradições. Até na guerra as novas invenções e estratégias retiravam gradualmente força e significado à cavalaria, ao castelo e a combate individual.” (MARQUES, 1986: 279).

Esta questão é interessante por nos conduzir à querela que se desenvolveu entre Álvaro Pelayo e o soberano português D. Afonso IV. Para uma breve descrição de D. Afonso e seu reinado, combinamos tanto as palavras de Marques na obra citada acima quanto o escrito de Armindo de Souza, 1325-1480, em História de Portugal: A Monarquia Feudal. D. Afonso IV ascende ao trono em 1325, sucedendo D. Dinis (1261-1325), com quem travou luta anos antes. Parte da nobreza lhe prestou auxilio em tal contenda, sobretudo como revanche às suas medidas centralizadoras, 
sendo retribuída por um tempo pelo novo rei, que chegou a ser o soberano feudal modelo - até se fortalecer e retomar as medidas centralizadoras do pai. A paz na Península foi um marco no seu reinado, salvo um curto intervalo de 1336-1339 quando veio novo conflito com Castela, resultado de más bodas entre a filha de D. Afonso IV e D. Afonso XI de Castela, além da oportunidade da nobreza castelhana, descontente com seu rei, apoiar o soberano português. A Cruzada contra os muçulmanos feita logo após a guerra veio a cimentar a amizade com o vizinho castelhano, que atacado, solicitou ajuda de toda a Cristandade e especificamente, dos reinos próximos, no que foi atendido por D. Afonso IV em pessoa; deste movimento militar podemos destacar a Batalha do Salado (1340) por meio da qual, mais tarde, recebeu o epíteto de o Bravo.

A guerra com Castela (1336-1339) empreendida por D. Afonso IV levou a uma sobretaxação e até mesmo ao confisco dos bens eclesiásticos, especialmente aos de Silves, local para onde Álvaro Pais fora designado pelo Papa João XXII, anos antes. Tomando o fato como injusto, Pelayo redige uma carta endereçada ao soberano (possivelmente entre 13361337) tratando do matrimônio do infante com D. Constança, bem como se justificando pelo seu não comparecimento nas Cortes, a qual fora convidado por carta real. Na mesma Álvaro censura duramente o rei português tanto pela guerra contra Castela, que causava malefícios a muitas gentes, quanto por fazê-las às custas de bens eclesiásticos, destinados a socorrer os pobres e necessitados. Uma segunda carta, mantinha os mesmos tons, além de exortar o fato de o rei ter cobrado impostos arbitrários da Igreja de Silves, sem antes ter pedido a autorização da Santa Sé e por conseguin- 


\section{Cadernos de Clio, Curitiba, n. ${ }^{\circ}$ 4, 2013}

te, ter violado a imunidade eclesiástica e desrespeitado a jurisdição episcopal.

Segundo as palavras de José Antônio de C. R. de Souza,

“[...] não cremos que os desentendimentos ocorridos entre o bispo de Silves e o monarca lusitano tenham apenas sido fruto de episódios circunstanciais. Na verdade, acreditamos que o motivo principal residiu basicamente na política centralizadora adotada por D. Afonso IV, seguindo as pegadas de seu pai, D. Dinis (1279-1325), e de seu avô, Afonso III (1248-1279), os quais, devido ao peso econômico e político do clero, tomaram proporcionalmente muito mais medidas contra o mesmo, do que em relação à nobreza, visto que os eclesiásticos, seculares ou regulares, impediam os soberanos de alcançarem seus propósitos aliados à burguesia. Aliás, pensamos ainda que não foi despropositadamente que João XXII, político experiente, nomeou D. Álvaro para o bispado de Silves.” (SOUZA, J. A. C., 2010: p. 85-86).

Em vista ao trecho recortado acima, observa-se que o soberano português tinha ciência da trajetória do Bispo de Silves, sobretudo, de sua ativa participação na luta empreendida anos antes entre João XXII e Luís $\mathrm{IV}^{6}$. Como Souza nos sugere, eis então um bom motivo para que se fosse prestada atenção ao frei, que por meio de suas atitudes poderia minar a política centralizadora que estava sendo empreendida. Em contrapartida, também vemos o apoio que lhe fora prestado ao pelo Papa que, ao mesmo

${ }^{6}$ Luta esta travada por conta da questão sucessório do Sacro-Império Romano Germânico. Para mais dados sobre esta questão, conferir As relações de poder na Idade Média Tardia de José Antônio de C. R. de Souza, página 11 e seguintes. 
tempo, queria ter presente em Portugal uma pessoa com pulso firme e devotada aos interesses da Igreja para coibir as ações das autoridades laicas que estavam a serviço da Coroa, principalmente em questões que pertenciam estritamente à esfera espiritual; ninguém mais conveniente, para tal encargo, do que um especialista em Utroque Iure e douto em tantos outros assuntos. Dito tudo isso, podemos tratar um pouco mais das ideias contidas no Speculum Regum e também das discussões de Morais Barbosa, tendo sempre como base a relação Sacerdotium-Imperium, no pensamento de Álvaro Pelayo.

\section{O Speculum Regum e a Teoria Política de Álvaro Pelayo}

O plano político é bastante abordado no início de nossa fonte devido ao momento em que fora redigida - vivia-se a euforia da vitória conquistada na Batalha do Salado (1340). Com o passar do tempo, o nível ético torna-se cada vez mais relevante em oposição ao político, acabando por dominar completamente sua parte final, como podemos observar pela intensa abordagem das virtudes (BARBOSA, 1972: 31-33). O Espelho dos Reis também é pobre no que tange à eclesiologia: tudo o que temos são referências dispersas ao longo de suas páginas, através das quais podemos deduzir o pensamento de Álvaro sobre o assunto. Assim sendo, observamos que a Igreja é a comunidade dos cristãos, vivos e mortos, onde Cristo é sua cabeça e seu chefe - de modo resumido, uma comunidade mística de salvação, onde no plano terreno o Papa é seu vigário uni- 
versal e chefe maior do conjunto da Cristandade ${ }^{7}$. Podemos até dizer que está dotado da Plenitudo Potestatis. Como muitos autores medievais, vemos a recorrência à Teoria dos Dois Gládios, elabora séculos antes pelo Papa Gelásio I (seu pontificado foi de 492 a 496), presente também na obra de Álvaro Pelayo; como defensor da causa curialista, observa-se a atribuição de ambos os gládios - o temporal e o espiritual - ao Sumo Pontífice, pois outrora Cristo atribuíra o mesmo a São Pedro e esse, por consequência, a seus sucessores direitos, os Papas.

Com base nesta premissa, e de acordo com a doutrina da Translatio imperii (que ainda no De Statu et Planctu Ecclesiae, Álvaro tenta refutar as asserções no opúsculo de Marsílio de Pádua, intitulado Sobre a translação do Império (SOUZA, 2010: 238)), o Papa é a origem e causa eficiente do poder temporal, assunto muito caro para o frei galego. Graças ao Pontífice, se originou o Império Ocidental e também o poder imperial do imperador - e por consequência, não cumprindo suas prerrogativas, o Papa tem o direito de julgá-lo e destituí-lo do poder; já o contrário não pode acontecer: a jurisdição do Papa vem de Deus e não do homem, sendo assim, a autoridade temporal não tem o direito de julgar o Pontífice (Álvaro Pelayo deixa claro que seu poder também provém de Deus, mas recebe-o por meio do Papa). No caso do Imperador, este é tido como minister Ecclesiae et Papatus, ou seja, advogado, defensor e protetor da fé católica e da Igre-

\footnotetext{
${ }^{7}$ Para não fugirmos em demasia de nova pesquisa, vale salientar apenas dois aspectos muito pertinentes levantados por José Antônio de Souza acerca das teorias opositoras de Marsílio de Pádua: 1 - Cristo não deixou nenhum chefe para a Igreja e São Pedro não teve nem exerceu nenhuma autoridade sobre os demais Apóstolos; 2 - Todos os sacerdotes, inclusive o papa, possuem autoridade igual (SOUZA, J. A., 2008: 281).
} 
ja de forma geral, e do Sumo Pontífice e do Papado em particular, tendo como obrigação defender a fé cristã de todos os males e adversários.

Em linhas gerais, esta é a clara distinção entre um poder e outro, bem como a determinação de que o poder temporal está submisso ao poder espiritual.

\begin{abstract}
“Álvaro Pais, estabelece, pois, duas ordens diferentes na vida humana: uma diz respeito à sua salvação eterna, e está supremamente confiada aos sacerdotes; a outra refere-se aos assuntos de ordem temporal, e o chefe supremo, nesta ordem de valores, é o Rei. O problema torna-se bem mais complexo, no entanto. Os próprios interesses temporais só são válidos enquanto contribuem para a total realização do homem. Deste modo, e porque o ser humano só se realiza completamente na beatitude eterna, mediante a visão directa de Deus, coloca-se o temporal em função do espiritual, a vida terrena em função da celeste e, como consequência ultima, o príncipe deve submeter-se em grande parte ao Papa e o Imperium ao Sacerdotium.” (BARBOSA, 1972: 147).
\end{abstract}

Entretanto, as explanações do Bispo de Silves tornam-se mais aprofundadas à medida em que desenvolve seu texto, justificando os motivos pelos quais atribui tal distinção. Ao rei (quando mencionamos tal titulação, nos referimos aos soberanos temporais de maneira geral - e nisso inclui-se o Imperador) cabem inúmeras tarefas, todas elas de ordem civil nesta esfera, como bem deixa claro Pelayo, seu poder é ilimitado e inquestionável, conforme própria atribuição de Deus, mesmo que o soberano seja um tirano.

Então, cumpre ao mandato da autoridade secular julgar as causas que são levadas a seu tribunal, aplicando-lhes a lei alicerçada na Justiça, legislar e ratificar leis para todos os setores da sociedade, bem como fazer com que as mesmas sejam cumpridas. Também lhe é devido ensinar seus 
súditos a serem virtuosos, bons cumpridores da lei - resultado pedagógico proveniente de sua própria boa conduta, guiada pela graça das virtudes cardeais; propiciar aos mesmos os meios para que obtenham o necessário para viver bem; manter a unidade política do reino e a paz entre seus súditos, assim como assegurar a ordem pública interna e as defesas do território contra ameaças estrangeiras. É interessante o papel da ética na obra de Pelayo - Barbosa sempre ressaltará o todo orgânico que a temática política, ética e metafísica formam no Speculum Regum. Por isso, conselhos como agir sempre com retidão, governando primeiramente a si e depois aos súditos, deixando de se conduzir pelas paixões, serão recorrentes e estarão perfeitamente imbricados ao compromisso político (PAIS, 1956: 93-133; SOUZA, J. A. C., 2010: 240-241). O poder temporal é espiritualizado por Pelayo tanto pela ética que permeia o rei (que deve portar as virtudes) como pela natureza espiritual de sua meta última governamental, que é a Bem-Aventurança (BARBOSA, 1972: 240-241).

Podemos então observar que embora Álvaro Pelayo pregue a supremacia do poder espiritual sobre o temporal, o primeiro jamais tem por intento neutralizar o poder do segundo (assim como o inverso também é válido). O fato principal é que ao longo de toda a Idade Média, Sacerdotium e Imperium necessitaram sempre um do outro para legitimar sua soberania, muito embora os choques provenientes dessa legitimação tenham desenvolvido inúmeros trabalhos em defesa de uma ou outra instituição e, quando não envoltos por debates teóricos, houveram embates com muito sangue envolvido.

O que vemos então com o frei galego é a transformação do poder secular no braço da Igreja, que toma às vezes de cabeça, dentre duma me- 
táfora a qual a Cristandade assume as a forma de corpo. Em vista que esse braço se pluraliza em múltiplos reis, o Papa acaba por ter seu poder estendido a todo o século, muito embora sua intromissão na esfera temporal seja tida como infratória e passível de incorrer no pecado, da mesma forma como um rei pode cair em tal infração:

"No tocante aos clérigos, ainda que tenham cometido um delito meramente secular, o monarca não tem o direito de coagi-los a comparecer ao seu tribunal, tanto porque gozam de foro próprio, quanto apenas lhe compete julgar os leigos e, pela mesma razão, não deve proferir sobre causas de natureza espiritual, porque estas são exclusivamente da alçada dos bispos, dos arcebispos e do papa ${ }^{8}$." (SOUZA, 2010: 280).

O que vemos, portanto, não é a subjugação das esferas, muito embora a autonomia temporal seja limitada em vista das delimitações impostas pelo poder espiritual, mas sim, a criação de uma esfera de poder onde o temporal se alia ao espiritual. Álvaro Pelayo então visa estabelecer um sistema explicativo demonstrando a relação entre as duas instâncias de poder, sistema esse onde os dois gládios se harmonizam e se auxiliam, tendo em vista o governo da Ecclesia e, um fim último, o bem-comum para posteriormente, todos os cristãos ingressarem no Reino Eterno.

Vemos, portanto, Álvaro Pelayo concordando com a premissa de que o Imperador, neste caso, é o senhor do mundo, mas faz a ressalva de que ele o é dentro de sua própria esfera de competência. Ao receber do Papa o gládio temporal, o faz sob a promessa de defender e servir a Igreja, bem como zelar pela Cristandade (lembrando também do fato de que todo

\footnotetext{
${ }^{8}$ No Speculum Regum, I, p. 104-106, Álvaro diz que nos assuntos de natureza civil, deve-se ouvir mais os príncipes do que os clérigos.
} 
clérigo está impedido de portar armas, a exceção daqueles que compõe as Ordens Militares). Também podemos lembrar das funções últimas de cada esfera - a das autoridades laicas, prover a boa vivência do homem na terra; quanto a das espirituais, que conduzi-las à Bem Aventurança - estando a última hierarquicamente acima da primeira.

\section{Conclusão}

Ao analisarmos os trabalhos de alguns dos autores que se dedicam a História Medieval portuguesa e especialmente a um recorte cronológico semelhante ao nosso, observamos claramente a opinião de que os séculos XIV e XV são responsáveis por intensas transformações na Cristandade latina, transformações estas que forjarão os pilares para o que conhecemos como “Era Moderna”. Almejamos com este trabalho, além de clarificar e levantar pontos importantes sobre a teoria política de Álvaro Pelayo, compreender este período ímpar da história que antecede, e que ao mesmo tempo, tornam-se o ponto de partida para eventos de grande magnitude vindouros. Voltando mais uma vez ao pensamento do Bispo de Silves, se observarmos bem suas palavras, veremos a temática da unidade como um assunto recorrente em sua obra:

“Paz é unidade. Discórdia é divisão - logo, multiplicidade. O caminho do múltiplo para o uno manifesta-se, a um tempo, como imposição metafísica, ética e política. A unidade é inerente ao espírito; a multiplicidade é própria da matéria. Daí a submissão da matéria ao espírito, do corpo à alma, do reino do mundo ao reino eterno, do Imperium ao Sacerdotium. Daí também que - a um nível ético - o príncipe deva viver de acordo com as virtudes, proporcionando aos súbditos condições para uma vida igualmente virtuosa, já que só assim eles atingirão a bem-aventurança celeste. Aí está também a ra- 
zão última de ser do próprio Estado, enquanto sociedade cujos membros estão em processo para Deus.” (BARBOSA, 1972: 284).

Observamos que, para além das questões de supremacia de um poder sobre outro, Álvaro sempre buscava pregar a unidade, tentando, por meio de suas teorias, formar um todo que tivesse o poder de manter a coesão e estabilidade da Societas christiana, pois outro caminho seria a crise e o fim certo da sociedade como os mesmos conheciam. Podemos encontrar justificativa para a obra de Álvaro Pelayo em algumas reflexões fornecidas por Jacques Le Goff.

Diz-nos o medievalista francês que a Igreja prestava grande ajuda aos reis, sacralizando o poder real e fazendo com que todos fossem obrigados a submeter-se a sua esfera de poder - quem a ela resistisse, resistia à ordem desejada por Deus. Mas, em contra partida e de forma ambígua, esta fazia uso do rei para controlar seus guerreiros, atribuindo à realeza a função de braço secular, executando as ordens da classe sacerdotal em seu lugar, esquivando-se da força física, da violência e derramamento de sangue que, como já dissemos anteriormente, era proibido para a ordem religiosa. Destaca-se também para esta realeza, sua função de governar e reger o povo de Deus em equidade e justiça, em velar pela paz e pela concórdia. Aqueles príncipes deviam proteger as igrejas, os servidores de Deus, as viúvas e os órfãos e todos os outros pobres e indigentes; esboçam-se assim os espelhos de príncipe em que os bispos manipulam ${ }^{9}$ os

${ }^{9}$ Le Goff coloca este termo, “manipulam”, em sua obra; entretanto, achamos mais conveniente usar a palavra "instruíam”, por não conter uma carga pejorativa em seu significado, tendo em vista que em vários casos, os autores redigiam tais 
príncipes, desde Luís, o Piedoso, até, no século XIII, São Luís, que se esforça por ser o rei-modelo, tanto no plano moral quando no espiritual (LE GOFF, 1984: 27-28).

De tudo o que foi dito, precisamos nos deter principalmente na seguinte expressão: “resistia à ordem desejada por Deus”. Essa ordem era justamente o que propunha Álvaro Pelayo escalando hierarquicamente as esferas de poder, compondo seu sistema de governança visando o equilíbrio da Cristandade. Barbosa irá sintetizar muito bem tal ideia, partindo também das explanações do Bispo de Silves, dizendo que “[...] Igreja e Estado são dois polos solidários de um corpo unitário, de natureza político-religiosa: a Cristandade” e que “[...] temos ser a Igreja, fundamentalmente, uma comunidade, a qual, mesmo quando representada em exclusivo pelo papa, age como um todo, e como um todo adora a Deus e lhe presta acção de graças em todos os momentos.” (BARBOSA, 1972: 298).

Como dito anteriormente, o embate de séculos entre Imperium e Sacerdotium havia-se a muito findado, culminando com uma aparente vitória que conferiu ao Papado quase um século de supremacia sobre a Cristandade, indo do pontificado de Inocêncio III (que se iniciou em 1193) ao término do de Bonifácio VIII (1303), fazendo com que a Instituição, além do mais, saísse dele fortalecida (KNOWLES \& OBOLENSKI, 1976: 10-12). Porém, com a série de querelas que envolveram Filipe, o Belo, de França e o Papa Bonifácio VIII, o monumento teocrático eclesiástico ruíra, a ponto de, por quase setenta anos, a Cúria Pontifícia ficar sujeita aos mandos e desmandos dos soberanos franceses. Tal fato marca o obras objetivando o bem do reino e cumprindo suas funções como evangelizadores. 
progresso da centralização do poder nas mãos dos soberanos dos vários reinos da Cristandade latina e, consigo, trás outras consequências ao clero, como a formação cada vez mais próxima de uma igreja nacional. Em paralelo a isso temos uma Guerra dos Cem Anos (1337-1353 - data canônica, embora o conflito tenha se desenvolvido de maneira intermitente) que, para além do que se imaginava, dividiria a Europa em dois blocos conflitantes entre si. Como agravante a tal situação, surgiria o Grande Cisma do Ocidente (1378-1417) que abalaria severamente o pilar moral desta sociedade - a própria Igreja - dando existência a não apenas um Papa, mas sim, dois, chegando a um terceiro no século XV (GIRARDI, 2012). Bicefalia. A Cristandade havia se transformado num monstro e o caos se instalado; o maior temor desta sociedade se concretizara.

Fora contra isso que Álvaro Pelayo e outros teóricos lutaram. Embora discordantes em várias ocasiões, todos buscavam a manutenção da ordem existente, defendendo os preceitos que julgavam como melhores e justos. Para concluir, gostaríamos de ressaltar que juntamente às premissas ditas acima, sempre houvera um fim último por trás desta ordem e do bem governar pregados, o qual Álvaro Pelayo deixa muito bem claro em seu Speculum Regum: conduzir os homens ao Reino de Deus e à BemAventurança Eterna. Para isso, deveriam os soberanos espirituais e temporais bem conduzi-los em sua passagem temporária pelo reino terreno o que consequentemente envolvia a necessidade de estar a Cristandade unidade e em paz, para que melhor pudesse auxiliar no bem estar dos filhos de Deus na Terra. 
Cadernos de Clio, Curitiba, n. ${ }^{\circ}$ 4, 2013

\section{Referências Bibliográficas}

\section{Fontes:}

PAIS, Álvaro. O Espelho dos Reis (Speculum Regum). Vol. I. Lisboa: Instituto de Alta Cultura, 1955.

PAIS, Álvaro. O Espelho dos Reis (Speculum Regum). Vol. II. Lisboa: Instituto de Alta Cultura, 1963.

\section{Bibliografia:}

ALMEIDA, Cybele Crossetti. Considerações sobre o uso político do conceito de justiça na obra legislativa de Afonso X, in: Anos 90, Porto Alegre, Programa de História da UFRGS: 16 ( 2002): 13-36.

ALMEIDA, Fortunato de. História da Igreja em Portugal (ed. De Damião Peres). Porto: Portucalense Editora, 1967, 4 vol.

BARBOSA, João Morais. A teoria política de Álvaro Pais no "Specvlvm Regvm": esboço duma fundamentação filosófico-jurídica. Lisboa: Ministério da Justiça, 1972.

BERRIEL, Marcelo Santiago. Cristão e súdito: representação social franciscana e poder régio em Portugal (1383-1450). Tese (Doutorado). Universidade Federal Fluminense. Programa de Pós-Graduação, História Social, 2007, pp. 77-85.

DIEHL, Rafael Mesquita; SANTANA, Eliane Veríssimo. "Vincere vitia et se ipsum virtus est morum - as virtudes como instrumentos políticos nos espelhos de príncipe de Egídio Romano e Álvaro Pelayo. In: V Congresso Internacional de História, 2011, Maringá. Anais do V Congresso Internacional de História, 2011.

FERNANDES, Fátima Regina. O Conceito de Império no Pensamento Político Tardo-Meideval. In: LIMA, Luís Filipe Silvério; SILVA, Luiz Geraldo (Orgs.). Facetas do Império na História: Conceitos e Métodos. São Paulo: Hucitec, 2008.

, A recepção do Direito Romano no Ocidente Europeu Medieval: Portugal, um caso de afirmação régia. In História: Questões \& Debates, n. 41, Curitiba, Editora UFPR, 2004, pp. 73-83. 
Poder e sociedade na Península Ibérica Medieval. In Humanas, n. 10, Curitiba, Editora UFPR, 2001, pp. 123-133.

O poder do relato na Idade Média Portuguesa: a Batalha do Salado de 1340. In Mosaico, vol. IV, ${ }^{\circ} 1$, 2011.

FILHO, Flávio Ferreira Paes. A práxis político-administrativa nos textos legais dos monarcas portugueses (séculos XIII-XIV). Tese (Doutorado). Universidade do Porto. Faculdade de Letras. Doutorado em História Medieval e do Renascimento, 2008.

GIRARDI, Leonardo. “A política pendular de D. Fernando I de Portugal (13671383) e sua relação com o Cisma do Ocidente (1378-1383).” In: Cadernos de Clio / PET História UFPR, n³, Curitiba, 2012, pp. 45-69.

KNOWLES, David, OBOLENSKY, Dimitri. Nova História da Igreja: a Idade Média. Petrópolis: Vozes, 1983, v. II.

LE GOFF, Jacques. A civilização do Ocidente medieval. Lisboa: Estampa, 1984, vol. II.

MARQUES, A. H. de Oliveira, Portugal na Crise dos Séculos XIV e XV. Lisboa: Ed. Presença, 1986.

PALÁCIOS MARTIN, B., "El mundo de las ideas políticas en los tratados doctrinales españoles: los espejos de príncipes" (1250-1350). In: Europa en los umbrales de la crisis: 1250-1350, XXI Semana de Estudios Medievales, Estella, 1994, Pamplona: Gobierno de Navarra, 1995.

PEDRERO-SÁNCHEZ, Maria Guadalupe. História da Idade Média: textos e testemunhas. São Paulo: Editora UNESP, 2000.

PIERRARD, Pierre. História da Igreja. São Paulo: Edições Paulinas, 1982.

RIBEIRO, Daniel Valle. Igreja e Estado na Idade Média. Belo Horizonte: Editora Lê, 1995.

SOUZA, Armênia Maria de. "A realeza cristã ibérica no Espelho dos Reis de frei Álvaro Pais (séc. XIV).” In Dimensões, vol. 26, 2011, p. 189-215.

SOUZA, Armindo de. “1325-1480”. In: MATTOSO, José (dir.). História de Portugal: A Monarquia Feudal (vol. II, 1096-1480). Lisboa: Editorial Estampa, 1993.

SOUZA, José A. de C. R. de. As relações de poder na Idade Média Tardia: Marsílio de Pádua, Álvaro Pais O. Min. e Guilherme de Ockham O. Min. Porto Alegre: EST Edições, 2010. 


\section{Cadernos de Clio, Curitiba, n. ${ }^{\circ}$ 4, 2013}

As causas eficiente e final do poder espiritual na visão de D. Frei Álvaro Pais. In: Anales del Seminario de Historia de la Filosofía. 2008.

, Um fillo de Gómez Chariño: Álvaro Pais; traxectoria e promocion al episcopado. In Revista Galega do Ensino, Santiago de Compostela, nº44, 2004, p.177-197.

VERGER, Jacques. Homens e saber na Idade Média. São Paulo: EDUSC, 1999. 